\title{
Haemato-biochemical Study: Induced Beta Cyfluthrin Repeated Toxicity with Reversal on Wistar Rats
}

\author{
H.C. Parmar*, J.K. Raval, J.M. Patel, P.D. Vihol, I.H. Kalyani and M.C. Prasad \\ Department of Veterinary Pathology, College of Veterinary Science and A. H. \\ Navsari Agricultural University, Navsari-396 450, Gujarat, India \\ *Corresponding author
}

\begin{abstract}
A B S T R A C T
Beta cyfluthrin is widely used multipurpose synthetic pyrethroid. Indiscriminate uses

Keywords

Beta cyfluthrin,

Pyrethroid,

Haemato-

bichemical

Alteration, Rat

Article Info

Accepted:

04 February 2019

Available Online:

10 March 2019

resulting to deleterious effects in animal metabolism. Present study has been designed to investigate the effects of beta cyfluthrin on haemato-biochemical alteration in both the sexes of Wistar rats (Rattus norvegicus). Beta cyfluthrin was orally administered, 38.0 $\mathrm{mg} / \mathrm{kg}$ b. wt. (high dose), $12.66 \mathrm{mg} / \mathrm{kg} \mathrm{b}$. wt. (mid dose), $4.22 \mathrm{mg} / \mathrm{kg} \mathrm{b}$. wt. (low dose) for 90 days with high dose recovery. Beta cyfluthrin caused marked reduction in $\mathrm{Hb}$ concentration, RBCs count, haematocrit, $\mathrm{MCH}$, platelets, lymphocytes whereas an increased in TLC and neutrophil count at different intervals in both the sexes. Serum activities of AST, ALT, ALP, LDH and concentration of total proteins, globulin, creatinine, blood urea nitrogen, glucose, total bilirubin, total cholesterol, triglyceride and total lipids was increased whereas albumin, A:G ratio, sodium and chlorides were significantly decreased. Results showed that liver and kidneys were affected due to toxicity of beta cyfluthrin. Recovery period brought all these parameters within normal range but lipid profile which remained at higher level even after withdrawal of treatment. Thus, beta cyfluthrin should be used with cautiously under areas before untargeted animals.
\end{abstract}

\section{Introduction}

Pesticides are the most effective means of pest eradication all over the world but their use has reached an alarming rate due to a number of adverse effects on non target organisms (Bhusan et al., 2013a). Pyrethroid pesticides are broadly divided in to type I and II, depending upon absence and presence of alpha cyno group, respectively and their produced behavioral changes (Sayim et al., 2005; Wolansky et al., 2006). Beta cyfluthrin, the refined form of synthetic pyrethroids are currently being used in many formulations around the world. It belongs to the type II class of synthetic pyrethroids and act as a contact and stomach poison. It is a nonsystemic chemical used to control ectoparasites in animals as topical application and also control of insects like cutworms, cockroaches, termites, mosquitoes, fleas, flies, tobacco budworm, etc. Beta cyfluthrin based insecticide formulations are available in the form of emulsifiable concentrates, wettable 
powder, aerosol, granules, liquid, oil-in-water emulsion and oil spray. Injudicious uses create detrimental effect on host. Pyrethroids are known to have toxic potential in mammals affecting liver, kidneys and their functions in either sex by a number of researchers (Tuzmen et al., 2008; Mani et al., 2004; Okuno et al., 1986; Sakr, 1999).

The aim of the study was to evaluate toxicity of beta cyfluthrin on wistar rats in serum haemato-biochemical changes. In addition, the study was extended up to concomitant recovery phase of fourteen days following ninety days of beta cyfluthrin exposure, to assess possible recovery from intoxication.

\section{Materials and Methods}

The toxicity study of beta cyfluthrin was carried out with maintained animal welfare protocol on 120 rats having 6-7 weeks of age, acclimatized one week to laboratory condition prior to dose administration. The animals were maintained under standard conditions of light and temperature provided, standard rat pellet feed (M/S VRK Nutritional Solutions, Pune) and water ad libitum throughout the study. Rats were randomly divided into six different groups with 10 males and 10 females in each group. Gr.1 to Gr.4 as a main study groups and Gr.5 acted as control recovery group while Gr.6 acted as high dose recovery group. After 90 days of oral dosing, beta cyfluthrin was discontinued for 14 days. Technical grade beta cyfluthrin (purity >99\%) procured from M/S Krishi Rasayan Exports Pvt. Ltd., Ahmedabad was dissolved in carboximethyl cellulose (CMC) and administered orally to rats of Gr. 2 to 4 in graded dose $(4.22 \mathrm{mg} / \mathrm{kg} \mathrm{b}$. wt, $12.66 \mathrm{mg} / \mathrm{kg} \mathrm{b}$. wt, $38.0 \mathrm{mg} / \mathrm{kg}$ b. wt.).

Rats were anaesthetized using diethyl ether for blood collection. Blood samples were collected from retro orbital venous plexus using rat capillaries at $28^{\text {th }}, 56^{\text {th }}$ and $90^{\text {th }}$ day
(For main study Gr.1 to 4) and $104^{\text {th }}$ day (recovery control and recovery high dose of Gr.5 and 6) of experiment for hematological in K2 EDTA (anticoagulant) containing vial and biochemical parameters estimations in plain vial for separation of serum samples. At the end day of experiment, the surviving rats of main experiment four groups (Gr.1 to 4 at 90 days) and recovery two groups (Gr.5 and 6 at 104 days) were subjected to terminal sacrifice by over dose of ether inhalation followed by cervical dislocation after collection of blood. The data generated during experiment were subjected to statistical procedure given by (Snedecor and Cochran, 1980).

\section{Results and Discussion}

\section{Haematological parameters}

A significant decrease in the mean of $\mathrm{Hb}$, RBCs count, haematocrit, $\mathrm{MCH}$, platelets, lymphocytes whereas an increased in of TLC and neutrophils count was observed in low dose (Gr.2), mid dose (Gr.3) and high dose (Gr.4) at different intervals (i.e. $28^{\text {th }}, 56^{\text {th }}$ and $90^{\text {th }}$ day) of beta cyfluthrin treatment (Table 1) but a few parameters like $\mathrm{MCH}$ and RBCs did not fall in line of above observation at $90^{\text {th }}$ day of treatment and parameters except TLC and neutrophils came in normal range during post recovery period of two weeks. In other words TLC and neutrophils count remained increased even after withdrawal of treatment in either sex (Table 2).

Pyrethroids are known to induce toxic effects on various haematopoitic tissues in two ways: either by interference with mature components flowing in peripheral blood or with development of such integral blood components (Bhushan et al., 2013a). A decreased count in total red cells in present study following beta cyfluthrin intoxication is an indicator of interference of the experimental pesticides as well as its 
metabolically broken down byproducts causing lysis of erythrocytes resulting in its decrease in circulation (Shakoori et al., 1990; Ahmad et al., 2009; Abbassy and Mossa, 2012). Decreased haematocrit value as observed in the present study correlate with reduced RBC count coupled with hypohaemoglobinaemia accompanied by hypoplasia of bone marrow and anemia (Pande, 2001; Jain et al., 2009; Abbassy \& Mossa, 2012). Decreased the value of $\mathrm{MCH}$ may be attributed to microcytic anemia following beta cyfluthrin intoxication quantitatively. Decrease in MCHC value seemed to be the result of microcytosis of red blood cells. Further increased value (\%) of total leucocytes count was found to be the outcome of an increase in neutrophil on one hand a decrease of lymphocyte count in the present study increase count of neutrophil would have been a outcome of stimulated granulocyte precursors to produce more neutrophils while cytotoxic effects of beta cyfluthrin on the immunological organs where lymphocytes are formed (Wang et al., 2009).

\section{Biochemical parameters}

A dose dependent significant $(\mathrm{P}<0.05)$ increase in the activities of AST, ALT, ALP and LDH was observed in both the sexes at all the dose levels (low, mid and high) when compared to the control group at $28^{\text {th }}, 56^{\text {th }}$ and $90^{\text {th }}$ day of treatment (Table 3 ). But recovery period brought theses enzyme activities within normal range (Table 4). Broadly the present finding supported the observations of a number of earlier workers (Bhushan et al., 2013a; Yadav and Saxena, 2014; Samia et al., 2017). The activities of theses liver enzymes increases due to various hepatotoxic xenobiotics substances. It has been suggested by various workers in past that such a rise in an above mentioned hepatic enzymes is the outcome of hepatotoxic effects produced by various agents. The hepatotoxic injuries due to any reason are held responsible for rise of these enzymes in blood circulation (Samia et al., 2017). Whereas it has been suggested that similar rise in the activities of ALP and LDH is due to hepatocytic proliferation or improper functioning of hepatobiliary system (Gupta and Kumar, 1991).

A significant $(\mathrm{P}<0.05)$ increase in serum concentration of total proteins and globulin whereas decrease in albumin and $\mathrm{A}: \mathrm{G}$ ratio were seen in all the groups (Gr.2, 3 and 4) at different interval period $\left(28^{\text {th }}, 56^{\text {th }}\right.$ and $\left.90^{\text {th }}\right)$ in either sex of the rats (Table 5) and became normal during recovery period (Table 6). An increase was recorded in total proteins concentration in serum of rats exposed to beta cyfluthrin in this study might be due to increased leakage of liver enzyme and disturbances in protein catabolism while a decreased in albumin concentration might be due to liver dysfunction and disturbance in the biosynthesis of albumin in hepatocytes (Shakoori et al., 1988). In contrast, increased level of globulin concentration might be due to the toxic stress of beta cyfluthrin (Rifat et al., 2012). Pyrethroids induced stress leads the release of adrenocorticotropic hormone (ACTH) activating secretion of cortisol by adrenal cortex (Hayes and Laws, 1991). The increase in this hormone leads to reduced cellular protein stores. Therefore protein synthesis by hepatocytes comes to be out into blood increasing the protein concentration (Bhushan et al., 2013b). Similar results including increase total protein and globulin while reduced albumin and $A: G$ ratio also reported in past by many researchers (Shakoori et al., 1988; Yousef et al., 2006; Hussain et al., 2009; Waggas, 2013; Samia et al., 2017) in pyrethroids treatment.

A significant $(\mathrm{P}<0.05)$ increase in serum concentration of creatinine, blood urea nitrogen, glucose and total bilirubin was noted in the groups (Gr. 3 and 4) at all the interval 
period $\left(28^{\text {th }}, 56^{\text {th }}\right.$ and $\left.90^{\text {th }}\right)$ in either sex of rats (Table 5). Suggesting that kidney damage caused by beta cyfluthrin is recovered in 14 days if the toxic agent is discontinued. Serum creatinine and BUN are two main parameters to judge the health of kidneys. Creatinine is the breakdown product of muscle protein while it cleared and execrated from the kidneys. Higher level seen in experiment Gr. 3 and 4 indicated excessive breakdown of muscle protein which was dose and duration dependent. The value in high dose recovery group (Gr.6) also suggested that the damage occurring in kidneys was amenable to recover properly. The increased bilirubin might be due to liver cell damage because liver played major role in bilirubin metabolism which probably was inflammation in the present study resulting in disturbed bile excretion, might be responsible for hyperbilirubinemia intoxicated rats (Bhushan et al., 2013b). High glucose level in serum was also the outcome of beta cyfluthin toxicity. Hyperglycemia might be due to involvement of adrenal medulla in treated rats. There is every likely hood that beta cyfluthrin might not have killed beta cells of Islets of Langerhans out right but could have depressed beta cells activity thus affecting glucose metabolism but it need further elucidation. Our results revealed the clear dose dependent increase in blood urea nitrogen and creatinine levels in serum by toxic effect of beta cyfluthrin exposure. The increased these parameters might be attributed to the decrease in glomerular filtration, tubules dysfunction and kidney damage (Verma et al., 2013). Similar results reported in past by many researchers (Yousef et al., 2006; Fetoui et al., 2009; Waggas, 2013; Samia et al., 2017).

A significant $(\mathrm{P}<0.05)$ increase in the level of serum total cholesterol, triglyceride and total lipids was seen in rats of treated Gr.2, 3 and 4 at all the intervals $\left(28^{\text {th }}, 56^{\text {th }}\right.$ and $\left.90^{\text {th }}\right)$ in either sex of rats (Table 7). The recovery period of 14 days did not bring improvement in lipid profile (Table 8). Suggesting that energy crisis developed during study period of 90 days continue. Any increase in the level of these forms might increase total lipids concentration in serum. One of the causes of increased total lipid concentration appears to be the disturbance of carbohydrate metabolism due to probable cytotoxic effect of beta cyfluthrin on cells of the pancreas leading to relative deficiency of insulin (Guyton and Hall, 2001).

Table.1 Hematological values in main groups at different time intervals

\begin{tabular}{|c|c|c|c|c|c|c|c|}
\hline \multirow{2}{*}{$\begin{array}{c}\text { Parameters } \\
\text { Studied }\end{array}$} & \multirow{2}{*}{$\begin{array}{c}\text { Groups } \\
\mathbf{N}=\mathbf{1 0}\end{array}$} & \multicolumn{3}{|c|}{ Male } & \multicolumn{3}{|c|}{ Female } \\
\hline & & Day 28 & Day 56 & Day 90 & Day 28 & Day 56 & Day 90 \\
\hline \multirow{4}{*}{$\begin{array}{c}\text { TLC } \\
\left(\times 1^{3} / \mu \mathrm{L}\right)\end{array}$} & Gr.1 & $7.65^{\mathrm{a}} \pm 0.35$ & $8.02^{\mathrm{a}} \pm 6.37$ & $7.03^{\mathrm{a}} \pm 0.41$ & $5.48^{\mathrm{a}} \pm 0.36$ & $6.37^{\mathrm{a}} \pm 0.18$ & $5.38^{\mathrm{a}} \pm 0.96$ \\
\hline & Gr.2 & $7.99^{\mathrm{a}} \pm 0.49$ & $8.80^{\mathrm{a}} \pm 7.35$ & $8.23^{\mathrm{a}} \pm 0.48$ & $5.72^{\mathrm{a}} \pm 0.30$ & $7.35^{\mathrm{b}} \pm 0.56$ & $6.13^{b c} \pm 0.78$ \\
\hline & Gr.3 & $8.30^{\mathrm{a}} \pm 0.62$ & $9.00^{\mathrm{a}} \pm 7.68$ & $8.47^{b} \pm 0.51$ & $5.99^{\mathrm{a}} \pm 0.42$ & $7.68^{\mathrm{b}} \pm 0.47$ & $6.77^{\mathrm{cd}} \pm 1.42$ \\
\hline & Gr.4 & $9.02^{\mathrm{a}} \pm 0.62$ & $9.41^{\mathrm{a}} \pm 8.61$ & $8.73^{b} \pm 0.49$ & $6.25^{\mathrm{a}} \pm 0.57$ & $8.61^{\mathrm{b}} \pm 0.47$ & $6.98^{d} \pm 0.81$ \\
\hline \multirow{4}{*}{$\begin{array}{c}\text { TEC } \\
\left(\times 10^{6} / \mu \mathrm{L}\right)\end{array}$} & Gr.1 & $7.98^{\mathrm{a}} \pm 0.12$ & $7.98^{\mathrm{a}} \pm 0.05$ & $8.43^{\mathrm{a}} \pm 0.12$ & $7.63^{\mathrm{a}} \pm 0.05$ & $7.43^{\mathrm{a}} \pm 0.10$ & $7.91^{\mathrm{a}} \pm 0.39$ \\
\hline & Gr.2 & $7.75^{\mathrm{a}} \pm 0.15$ & $7.76^{\mathrm{a}} \pm 0.12$ & $8.11^{\mathrm{ab}} \pm 0.15$ & $7.32^{\mathrm{a}} \pm 0.12$ & $7.26^{\mathrm{a}} \pm 0.06$ & $7.36^{b} \pm 0.32$ \\
\hline & Gr.3 & $7.81^{\mathrm{a}} \pm 0.09$ & $7.80^{\mathrm{a}} \pm 0.09$ & $8.02^{b} \pm 0.09$ & $7.33^{\mathrm{a}} \pm 0.09$ & $7.21^{\mathrm{a}} \pm 0.10$ & $7.33^{b} \pm 0.19$ \\
\hline & Gr.4 & $7.76^{\mathrm{a}} \pm 0.08$ & $7.71^{b} \pm 0.07$ & $7.71^{\mathrm{b}} \pm 0.14$ & $7.12^{\mathrm{b}} \pm 0.07$ & $7.12^{\mathrm{b}} \pm 0.10$ & $7.29^{b} \pm 0.42$ \\
\hline \multirow{3}{*}{$\underset{(\mathrm{g} / \mathrm{dL})}{\mathbf{H b}}$} & Gr.1 & $15.50^{\mathrm{a}} \pm 0.17$ & $16.19^{\mathrm{a}} \pm 0.15$ & $15.99^{\mathrm{a}} \pm 0.23$ & $15.28^{\mathrm{a}} \pm 0.09$ & $15.17^{\mathrm{a}} \pm 0.21$ & $15.87^{\mathrm{a}} \pm 0.43$ \\
\hline & Gr.2 & $14.71^{\mathrm{ab}} \pm 0.33$ & $15.24^{\mathrm{ab}} \pm 0.16$ & $15.53^{\mathrm{b}} \pm 0.31$ & $14.58^{\mathrm{ab}} \pm 0.23$ & $14.21^{\mathrm{ab}} \pm 0.25$ & $14.78^{b} \pm 0.79$ \\
\hline & Gr.3 & $14.86^{\mathrm{ab}} \pm 0.31$ & $14.76^{\mathrm{ab}} \pm 0.30$ & $14.89^{b} \pm 0.35$ & $14.52^{\mathrm{ab}} \pm 0.14$ & $14.10^{\mathrm{b}} \pm 0.27$ & $14.57^{b} \pm 0.84$ \\
\hline
\end{tabular}




\begin{tabular}{|c|c|c|c|c|c|c|c|}
\hline & Gr.4 & $14.51^{b} \pm 0.27$ & $14.66^{\mathrm{b}} \pm 0.35$ & $14.59^{b} \pm 0.35$ & $14.15^{\mathrm{b}} \pm 0.20$ & $13.73^{b} \pm 0.22$ & $14.53^{b} \pm 0.64$ \\
\hline \multirow{4}{*}{$\begin{array}{l}\text { Haematocrit } \\
\text { /PCV }(\%)\end{array}$} & Gr.1 & $44.05^{\mathrm{a}} \pm 0.47$ & $44.27^{\mathrm{a}} \pm 0.36$ & $46.72^{\mathrm{a}} \pm 0.56$ & $42.55^{\mathrm{a}} \pm 0.53$ & $42.66^{a} \pm 0.41$ & $43.80^{a} \pm 1.34$ \\
\hline & Gr.2 & $42.76^{\mathrm{ab}} \pm 0.56$ & $43.18^{\mathrm{ab}} \pm 0.29$ & $45.07^{\mathrm{ab}} \pm 0.42$ & $40.89^{b} \pm 0.52$ & $41.47^{\mathrm{ab}} \pm 0.43$ & $42.34^{b} \pm 1.09$ \\
\hline & Gr.3 & $42.84^{\mathrm{ab}} \pm 0.30$ & $41.91^{\mathrm{ab}} \pm 0.40$ & $44.20^{b} \pm 0.62$ & $40.92^{\mathrm{b}} \pm 0.32$ & $40.99^{b} \pm 0.37$ & $41.51^{c} \pm 1.87$ \\
\hline & Gr.4 & $42.48^{\mathrm{b}} \pm 0.47$ & $41.42^{b} \pm 0.37$ & $42.56^{c} \pm 0.40$ & $40.94^{b} \pm 0.46$ & $40.40^{\mathrm{b}} \pm 0.32$ & $41.27^{c} \pm 1.41$ \\
\hline \multirow{4}{*}{$\begin{array}{c}\text { MCV } \\
(f L)\end{array}$} & Gr.1 & $55.29^{\mathrm{a}} \pm 0.83$ & $53.49^{\mathrm{a}} \pm 1.03$ & $55.51^{\mathrm{a}} \pm 1.12$ & $55.83^{\mathrm{a}} \pm 0.98$ & $57.50^{\mathrm{a}} \pm 0.75$ & $58.10^{\mathrm{a}} \pm 1.57$ \\
\hline & Gr.2 & $55.28^{\mathrm{a}} \pm 0.66$ & $52.91^{\mathrm{a}} \pm 0.73$ & $55.02^{\mathrm{a}} \pm 0.72$ & $55.92^{\mathrm{a}} \pm 0.57$ & $57.11^{\mathrm{a}} \pm 0.54$ & $57.61^{\mathrm{a}} \pm 1.50$ \\
\hline & Gr.3 & $54.92^{\mathrm{a}} \pm 0.51$ & $52.92^{\mathrm{a}} \pm 1.14$ & $55.15^{\mathrm{a}} \pm 0.84$ & $55.89^{a} \pm 0.36$ & $56.92^{\mathrm{a}} \pm 0.49$ & $56.61^{\mathrm{a}} \pm 2.49$ \\
\hline & Gr.4 & $54.95^{\mathrm{a}} \pm 0.52$ & $53.18^{\mathrm{a}} \pm 1.50$ & $55.39^{\mathrm{a}} \pm 1.15$ & $55.95^{\mathrm{a}} \pm 0.66$ & $56.85^{\mathrm{a}} \pm 0.95$ & $56.71^{\mathrm{a}} \pm 2.89$ \\
\hline \multirow{4}{*}{$\begin{array}{c}\text { MCH } \\
(\mathbf{p g})\end{array}$} & Gr.1 & $19.24^{\mathrm{a}} \pm 0.29$ & $19.23^{\mathrm{a}} \pm 0.23$ & $20.29^{a} \pm 0.17$ & $20.04^{a} \pm 0.18$ & $20.24^{\mathrm{a}} \pm 0.10$ & $21.58^{a} \pm 1.02$ \\
\hline & Gr.2 & $19.06^{\mathrm{a}} \pm 0.62$ & $18.69^{\mathrm{a}} \pm 0.30$ & $19.66^{\mathrm{ab}} \pm 0.11$ & $19.94^{\mathrm{a}} \pm 0.11$ & $19.78^{\mathrm{a}} \pm 0.36$ & $20.22^{\mathrm{ab}} \pm 0.42$ \\
\hline & Gr.3 & $19.07^{\mathrm{a}} \pm 0.46$ & $18.63^{\mathrm{a}} \pm 0.52$ & $19.44^{\mathrm{ab}} \pm 0.26$ & $19.95^{\mathrm{a}} \pm 0.19$ & $19.93^{\mathrm{a}} \pm 0.41$ & $19.93^{b} \pm 0.99$ \\
\hline & Gr.4 & $18.80^{\mathrm{a}} \pm 0.45$ & $18.88^{\mathrm{a}} \pm 0.83$ & $19.02^{\mathrm{b}} \pm 0.18$ & $19.44^{\mathrm{a}} \pm 0.38$ & $19.63^{\mathrm{a}} \pm 0.64$ & $20.13^{\mathrm{ab}} \pm 1.53$ \\
\hline \multirow{4}{*}{$\begin{array}{l}\text { MCHC } \\
(\mathrm{g} / \mathrm{dL})\end{array}$} & Gr.1 & $35.20^{\mathrm{a}} \pm 0.37$ & $36.18^{\mathrm{a}} \pm 0.24$ & $34.25^{\mathrm{a}} \pm 0.45$ & $35.67^{\mathrm{a}} \pm 0.47$ & $35.49^{\mathrm{a}} \pm 0.48$ & $36.08^{\mathrm{a}} \pm 2.40$ \\
\hline & Gr.2 & $34.43^{\mathrm{a}} \pm 0.84$ & $35.28^{\mathrm{a}} \pm 0.29$ & $34.48^{\mathrm{a}} \pm 0.73$ & $35.65^{\mathrm{a}} \pm 0.35$ & $34.28^{\mathrm{a}} \pm 0.62$ & $34.91^{\mathrm{a}} \pm 1.24$ \\
\hline & Gr.3 & $34.68^{\mathrm{a}} \pm 0.66$ & $35.23^{\mathrm{a}} \pm 0.67$ & $33.87^{\mathrm{a}} \pm 1.01$ & $35.49^{\mathrm{a}} \pm 0.58$ & $34.44^{\mathrm{a}} \pm 0.73$ & $35.17^{\mathrm{a}} \pm 2.53$ \\
\hline & Gr.4 & $34.21^{\mathrm{a}} \pm 0.77$ & $35.40^{\mathrm{a}} \pm 0.80$ & $34.27^{\mathrm{a}} \pm 0.67$ & $34.60^{\mathrm{a}} \pm 0.55$ & $33.99^{\mathrm{a}} \pm 0.59$ & $35.22^{\mathrm{a}} \pm 1.37$ \\
\hline \multirow{4}{*}{$\begin{array}{c}\text { Platelet } \\
\left(\times 10^{3} / \mu \mathrm{L}\right)\end{array}$} & Gr.1 & $928.00^{\mathrm{a}} \pm 26.97$ & $968.80^{\mathrm{a}} \pm 25.96$ & $797.30^{\mathrm{a}} \pm 22.15$ & $890.10^{\mathrm{a}} \pm 25.60$ & $925.80^{\mathrm{a}} \pm 15.12$ & $829.10^{\mathrm{a}} \pm 40.66$ \\
\hline & Gr.2 & $916.90^{\mathrm{a}} \pm 18.96$ & $952.10^{\mathrm{a}} \pm 20.55$ & $679.20^{b} \pm 35.81$ & $869.10^{\mathrm{ab}} \pm 17.05$ & $914.10^{\mathrm{ab}} \pm 38.00$ & $746.50^{b} \pm 60.26$ \\
\hline & Gr.3 & $908.60^{\mathrm{a}} \pm 17.99$ & $947.30^{\mathrm{a}} \pm 21.38$ & $681.80^{b} \pm 37.97$ & $852.70^{\mathrm{ab}} \pm 21.62$ & $864.60^{b} \pm 12.43$ & $730.00^{b} \pm 53.13$ \\
\hline & Gr.4 & $887.90^{\mathrm{a}} \pm 12.44$ & $921.70^{\mathrm{a}} \pm 15.02$ & $629.50^{b} \pm 42.78$ & $843.10^{\mathrm{ab}} \pm 34.35$ & $853.00^{b} \pm 28.75$ & $662.10^{b} \pm 102.61$ \\
\hline \multirow{4}{*}{$\begin{array}{c}\text { Lymphocyte } \\
(\%)\end{array}$} & Gr.1 & $74.62^{\mathrm{a}} \pm 4.02$ & $80.96^{\mathrm{a}} \pm 0.59$ & $81.17^{\mathrm{a}} \pm 0.73$ & $77.27^{a} \pm 1.36$ & $81.23^{\mathrm{a}} \pm 0.69$ & $81.61^{a} \pm 2.89$ \\
\hline & Gr.2 & $71.72^{\mathrm{ab}} \pm 3.15$ & $78.69^{b} \pm 0.63$ & $78.83^{b} \pm 0.76$ & $76.54^{\mathrm{a}} \pm 1.82$ & $79.61^{b} \pm 1.12$ & $79.49^{b} \pm 3.45$ \\
\hline & Gr.3 & $70.00^{b c} \pm 4.12$ & $78.24^{b} \pm 0.85$ & $77.79^{\mathrm{b}} \pm 1.02$ & $75.90^{\mathrm{a}} \pm 0.90$ & $79.26^{\mathrm{b}} \pm 0.66$ & $78.64^{b} \pm 3.03$ \\
\hline & Gr.4 & $67.11^{c} \pm 5.90$ & $77.16^{\mathrm{b}} \pm 0.73$ & $76.87^{b} \pm 1.75$ & $74.66^{\mathrm{a}} \pm 1.37$ & $78.13^{b} \pm 0.87$ & $78.42^{b} \pm 2.88$ \\
\hline \multirow{4}{*}{$\begin{array}{c}\text { Monocyte } \\
(\%)\end{array}$} & Gr.1 & $3.08^{\mathrm{a}} \pm 0.11$ & $2.59^{\mathrm{a}} \pm 0.10$ & $2.69^{\mathrm{a}} \pm 0.15$ & $2.68^{\mathrm{a}} \pm 0.16$ & $2.48^{\mathrm{a}} \pm 0.12$ & $2.37^{\mathrm{a}} \pm 0.42$ \\
\hline & Gr.2 & $2.96^{\mathrm{a}} \pm 0.14$ & $2.55^{\mathrm{a}} \pm 0.08$ & $2.65^{\mathrm{a}} \pm 0.07$ & $2.66^{\mathrm{a}} \pm 0.14$ & $2.41^{\mathrm{a}} \pm 0.06$ & $2.22^{\mathrm{a}} \pm 0.36$ \\
\hline & Gr.3 & $2.87^{\mathrm{a}} \pm 0.13$ & $2.50^{\mathrm{a}} \pm 0.10$ & $2.62^{\mathrm{a}} \pm 0.07$ & $2.62^{\mathrm{a}} \pm 0.16$ & $2.37^{\mathrm{a}} \pm 0.08$ & $2.15^{\mathrm{a}} \pm 0.40$ \\
\hline & Gr.4 & $2.97^{\mathrm{a}} \pm 0.10$ & $2.49^{\mathrm{a}} \pm 0.12$ & $2.56^{\mathrm{a}} \pm 0.10$ & $2.53^{\mathrm{a}} \pm 0.15$ & $2.38^{\mathrm{a}} \pm 0.05$ & $2.23^{a} \pm 0.37$ \\
\hline \multirow{4}{*}{$\begin{array}{c}\text { Neutrophils } \\
(\%)\end{array}$} & Gr.1 & $19.40^{\mathrm{a}} \pm 1.34$ & $13.75^{\mathrm{a}} \pm 0.96$ & $13.33^{\mathrm{a}} \pm 0.84$ & $17.95^{\mathrm{a}} \pm 1.10$ & $13.39^{\mathrm{a}} \pm 0.82$ & $12.72^{\mathrm{a}} \pm 2.27$ \\
\hline & Gr.2 & $22.52^{\mathrm{ab}} \pm 1.06$ & $16.16^{\mathrm{b}} \pm 0.75$ & $15.72^{\mathrm{ab}} \pm 0.74$ & $18.10^{\mathrm{a}} \pm 1.66$ & $15.28^{\mathrm{b}} \pm 1.08$ & $15.49^{b} \pm 3.87$ \\
\hline & Gr.3 & $24.63^{b c} \pm 1.29$ & $16.76^{b} \pm 0.92$ & $16.89^{b} \pm 1.03$ & $18.88^{a} \pm 0.70$ & $15.87^{b} \pm 0.62$ & $16.51^{b} \pm 2.89$ \\
\hline & Gr.4 & $27.62^{c} \pm 1.92$ & $17.95^{\mathrm{b}} \pm 0.91$ & $17.97^{b} \pm 1.89$ & $20.21^{\mathrm{a}} \pm 1.88$ & $17.09^{b} \pm 0.96$ & $16.85^{b} \pm 2.90$ \\
\hline \multirow{4}{*}{$\begin{array}{c}\text { Eosinophils } \\
(\%)\end{array}$} & Gr.1 & $2.70^{\mathrm{a}} \pm 0.30$ & $2.50^{\mathrm{a}} \pm 0.34$ & $2.80^{\mathrm{a}} \pm 0.25$ & $2.60^{\mathrm{a}} \pm 0.34$ & $2.70^{\mathrm{a}} \pm 0.30$ & $2.70^{\mathrm{a}} \pm 1.16$ \\
\hline & Gr.2 & $2.50^{\mathrm{a}} \pm 0.27$ & $2.30^{\mathrm{a}} \pm 0.30$ & $2.60^{\mathrm{a}} \pm 0.22$ & $2.40^{\mathrm{a}} \pm 0.22$ & $2.50^{\mathrm{a}} \pm 0.17$ & $2.50^{\mathrm{a}} \pm 0.85$ \\
\hline & Gr.3 & $2.30^{\mathrm{a}} \pm 0.21$ & $2.20^{\mathrm{a}} \pm 0.20$ & $2.50^{\mathrm{a}} \pm 0.22$ & $2.30^{\mathrm{a}} \pm 0.26$ & $2.30^{\mathrm{a}} \pm 0.26$ & $2.40^{\mathrm{a}} \pm 0.70$ \\
\hline & Gr.4 & $2.10^{\mathrm{a}} \pm 0.23$ & $2.10^{\mathrm{a}} \pm 0.23$ & $2.40^{\mathrm{a}} \pm 0.22$ & $2.10^{\mathrm{a}} \pm 0.23$ & $2.20^{\mathrm{a}} \pm 0.20$ & $2.20^{\mathrm{a}} \pm 0.79$ \\
\hline \multirow{4}{*}{$\begin{array}{c}\text { Basophils } \\
(\%)\end{array}$} & Gr.1 & $0.20^{\mathrm{a}} \pm 0.13$ & $0.30^{\mathrm{a}} \pm 0.30$ & $0.20^{\mathrm{a}} \pm 0.13$ & $0.30^{\mathrm{a}} \pm 0.15$ & $0.20^{\mathrm{a}} \pm 0.13$ & $0.30^{\mathrm{a}} \pm 0.48$ \\
\hline & Gr.2 & $0.20^{\mathrm{a}} \pm 0.13$ & $0.30^{\mathrm{a}} \pm 0.30$ & $0.20^{\mathrm{a}} \pm 0.13$ & $0.30^{\mathrm{a}} \pm 0.15$ & $0.20^{\mathrm{a}} \pm 0.13$ & $0.30^{\mathrm{a}} \pm 0.48$ \\
\hline & Gr.3 & $0.20^{\mathrm{a}} \pm 0.13$ & $0.30^{\mathrm{a}} \pm 0.30$ & $0.20^{\mathrm{a}} \pm 0.13$ & $0.30^{\mathrm{a}} \pm 0.15$ & $0.20^{\mathrm{a}} \pm 0.13$ & $0.30^{\mathrm{a}} \pm 0.48$ \\
\hline & Gr.4 & $0.20^{\mathrm{a}} \pm 0.13$ & $0.30^{\mathrm{a}} \pm 0.30$ & $0.20^{\mathrm{a}} \pm 0.13$ & $0.30^{\mathrm{a}} \pm 0.15$ & $0.20^{\mathrm{a}} \pm 0.13$ & $0.30^{\mathrm{a}} \pm 0.48$ \\
\hline
\end{tabular}

Note: Means bearing different superscript in a column differ significantly $(\mathrm{P}<0.05)$. 
Table.2 Haematological values in recovery groups at 104th day

\begin{tabular}{|c|c|c|c|}
\hline \multirow[t]{2}{*}{ Parameters Studied } & \multirow{2}{*}{$\begin{array}{c}\text { Groups } \\
\mathbf{N}=10\end{array}$} & Male & Female \\
\hline & & Mean \pm SE & Mean \pm SE \\
\hline \multirow{2}{*}{$\begin{array}{c}\text { TLC } \\
\left(\times 10^{3} / \mu L\right)\end{array}$} & Gr.5 & $7.65^{\mathrm{a}} \pm 0.23$ & $5.15^{\mathrm{a}} \pm 0.19$ \\
\hline & Gr.6 & $8.45^{\mathrm{b}} \pm 0.28$ & $5.38^{\mathrm{a}} \pm 0.15$ \\
\hline \multirow{2}{*}{$\begin{array}{c}\text { TEC } \\
\left(\times 10^{6} / \mu \mathrm{L}\right)\end{array}$} & Gr.5 & $8.37^{\mathrm{a}} \pm 0.16$ & $7.63^{\mathrm{a}} \pm 0.15$ \\
\hline & Gr.6 & $8.25^{\mathrm{a}} \pm 0.16$ & $7.52^{\mathrm{a}} \pm 0.07$ \\
\hline \multirow{2}{*}{$\begin{array}{c}\mathbf{H b} \\
(\mathrm{g} / \mathrm{dL}\end{array}$} & Gr.5 & $16.34^{\mathrm{a}} \pm 0.18$ & $15.47^{\mathrm{a}} \pm 0.18$ \\
\hline & Gr.6 & $16.10^{\mathrm{a}} \pm 0.27$ & $15.16^{\mathrm{a}} \pm 0.18$ \\
\hline \multirow[t]{2}{*}{ Hematocrit / PCV (\%) } & Gr.5 & $48.10^{\mathrm{a}} \pm 0.39$ & $43.80^{\mathrm{a}} \pm 0.99$ \\
\hline & Gr.6 & $47.49^{\mathrm{a}} \pm 0.70$ & $44.24^{\mathrm{a}} \pm 0.39$ \\
\hline \multirow{2}{*}{$\begin{array}{c}\text { MCV } \\
\text { (fL) }\end{array}$} & Gr.5 & $57.67^{\mathrm{a}} \pm 1.20$ & $58.96^{\mathrm{a}} \pm 1.16$ \\
\hline & Gr.6 & $57.68^{\mathrm{a}} \pm 0.98$ & $58.90^{\mathrm{a}} \pm 0.70$ \\
\hline \multirow{2}{*}{$\begin{array}{c}\mathrm{MCH} \\
(\mathbf{p g})\end{array}$} & Gr.5 & $19.61^{\mathrm{a}} \pm 0.52$ & $20.33^{\mathrm{a}} \pm 0.28$ \\
\hline & Gr.6 & $19.54^{\mathrm{a}} \pm 0.31$ & $20.18^{a} \pm 0.24$ \\
\hline \multirow{2}{*}{$\begin{array}{c}\text { MCHC } \\
(\mathrm{g} / \mathrm{dL})\end{array}$} & Gr.5 & $33.98^{\mathrm{a}} \pm 0.31$ & $34.54^{\mathrm{a}} \pm 0.50$ \\
\hline & Gr.6 & $33.90^{\mathrm{a}} \pm 0.29$ & $34.29^{a} \pm 0.50$ \\
\hline \multirow{2}{*}{$\begin{array}{l}\text { Platelet } \\
\left(\times 10^{3} / \mu \mathrm{L}\right.\end{array}$} & Gr.5 & $774.40^{\mathrm{a}} \pm 33.82$ & $773.50^{\mathrm{a}} \pm 16.34$ \\
\hline & Gr.6 & $733.90^{\mathrm{a}} \pm 25.41$ & $755.30^{\mathrm{a}} \pm 22.95$ \\
\hline \multirow{2}{*}{$\begin{array}{c}\text { Lymphocyte } \\
(\%)\end{array}$} & Gr.5 & $80.07^{\mathrm{a}} \pm 0.86$ & $76.85^{\mathrm{a}} \pm 0.03$ \\
\hline & Gr.6 & $77.28^{\mathrm{a}} \pm 0.84$ & $75.48^{\mathrm{a}} \pm 0.55$ \\
\hline \multirow{2}{*}{$\begin{array}{c}\text { Monocyte } \\
(\%)\end{array}$} & Gr.5 & $2.66^{\mathrm{a}} \pm 0.10$ & $2.31^{\mathrm{a}} \pm 0.16$ \\
\hline & Gr.6 & $2.71^{\mathrm{a}} \pm 0.14$ & $2.31^{\mathrm{a}} \pm 0.10$ \\
\hline \multirow{2}{*}{$\begin{array}{l}\text { Neutrophils } \\
\quad(\%)\end{array}$} & Gr.5 & $14.37^{\mathrm{a}} \pm 0.63$ & $18.14^{\mathrm{a}} \pm 0.99$ \\
\hline & Gr.6 & $17.11^{\mathrm{b}} \pm 0.94$ & $19.57^{\mathrm{a}} \pm 0.64$ \\
\hline \multirow{2}{*}{$\begin{array}{c}\text { Eosinophils } \\
(\%)\end{array}$} & Gr.5 & $2.70^{\mathrm{a}} \pm 0.26$ & $2.50^{\mathrm{a}} \pm 0.22$ \\
\hline & Gr.6 & $2.70^{\mathrm{a}} \pm 0.21$ & $2.50^{\mathrm{a}} \pm 0.17$ \\
\hline \multirow{2}{*}{$\begin{array}{c}\text { Basophils } \\
(\%)\end{array}$} & Gr.5 & $0.20^{\mathrm{a}} \pm 0.13$ & $0.20^{\mathrm{a}} \pm 0.13$ \\
\hline & Gr.6 & $0.20^{\mathrm{a}} \pm 0.13$ & $0.20^{\mathrm{a}} \pm 0.13$ \\
\hline
\end{tabular}

Note: Bearing different superscripts in a column differ significantly $(\mathrm{P}<0.05)$.

Table.3 Average enzyme activities values in different groups at different time intervals

\begin{tabular}{|c|c|c|c|c|c|c|c|}
\hline \multirow{2}{*}{$\begin{array}{l}\text { Parameters } \\
\text { Studied }\end{array}$} & \multirow{2}{*}{$\begin{array}{c}\text { Groups } \\
\mathbf{N}=10\end{array}$} & \multicolumn{3}{|c|}{ Male } & \multicolumn{3}{|c|}{ Female } \\
\hline & & Day 28 & Day 56 & Day 90 & Day 28 & Day 56 & Day 90 \\
\hline \multirow{4}{*}{$\begin{array}{c}\text { AST } \\
(\mathbf{U} / \mathbf{L})\end{array}$} & Gr.1 & $69.78^{\mathrm{a}} \pm 4.40$ & $67.52^{\mathrm{a}} \pm 6.22$ & $74.02^{\mathrm{a}} \pm 5.10$ & $83.25^{\mathrm{a}} \pm 4.93$ & $84.18^{\mathrm{a}} \pm 7.67$ & $83.72^{\mathrm{a}} \pm 7.02$ \\
\hline & Gr.2 & $152.45^{\mathrm{b}} \pm 10.18$ & $157.47^{\mathrm{b}} \pm 10.03$ & $150.20^{\mathrm{b}} \pm 9.13$ & $170.79^{\mathrm{b}} \pm 12.49$ & $171.44^{\mathrm{b}} \pm 9.39$ & $162.96^{b} \pm 8.18$ \\
\hline & Gr.3 & $167.66^{b} \pm 8.83$ & $150.53^{b} \pm 11.77$ & $153.80^{b} \pm 10.28$ & $195.53^{b} \pm 14.85$ & $179.10^{\mathrm{b}} \pm 11.49$ & $174.71^{b} \pm 11.94$ \\
\hline & Gr.4 & $178.04^{b} \pm 9.53$ & $159.71^{\mathrm{b}} \pm 11.32$ & $180.32^{\mathrm{c}} \pm 12.24$ & $199.07^{\mathrm{b}} \pm 13.43$ & $185.84^{\mathrm{b}} \pm 7.19$ & $188.22^{\mathrm{b}} \pm 12.26$ \\
\hline \multirow{4}{*}{$\begin{array}{l}\text { ALT } \\
(\mathbf{U} / \mathbf{L})\end{array}$} & Gr.1 & $29.03^{\mathrm{a}} \pm 2.99$ & $27.98^{\mathrm{a}} \pm 2.82$ & $30.32^{\mathrm{a}} \pm 2.99$ & $28.45^{\mathrm{a}} \pm 2.26$ & $29.43^{\mathrm{a}} \pm 2.58$ & $31.67^{a} \pm 2.48$ \\
\hline & Gr.2 & $42.53^{\mathrm{a}} \pm 3.55$ & $51.64^{\mathrm{b}} \pm 4.48$ & $52.38^{\mathrm{b}} \pm 5.65$ & $40.69^{a} \pm 3.15$ & $47.09^{b} \pm 5.15$ & $57.34^{b} \pm 3.79$ \\
\hline & Gr.3 & $60.68^{\mathrm{b}} \pm 5.72$ & $59.97^{\mathrm{b}} \pm 6.35$ & $58.96^{\mathrm{b}} \pm 4.62$ & $49.63^{\mathrm{b}} \pm 4.03$ & $52.42^{\mathrm{b}} \pm 4.55$ & $61.56^{b} \pm 6.15$ \\
\hline & Gr.4 & $62.40^{\mathrm{b}} \pm 6.27$ & $60.74^{\mathrm{b}} \pm 6.04$ & $64.20^{\mathrm{b}} \pm 5.45$ & $66.67^{c} \pm 5.33$ & $69.51^{c} \pm 4.55$ & $77.57^{c} \pm 6.21$ \\
\hline \multirow{4}{*}{$\begin{array}{l}\text { ALP } \\
\text { (U/L) }\end{array}$} & Gr.1 & $76.85^{\mathrm{a}} \pm 6.00$ & $73.80^{\mathrm{a}} \pm 6.84$ & $72.72^{\mathrm{a}} \pm 6.37$ & $71.76^{\mathrm{a}} \pm 5.12$ & $82.60^{\mathrm{a}} \pm 7.61$ & $78.38^{\mathrm{a}} \pm 5.86$ \\
\hline & Gr.2 & $174.90^{b} \pm 16.74$ & $176.10^{\mathrm{b}} \pm 14.48$ & $196.01^{\mathrm{b}} \pm 13.44$ & $118.72^{\mathrm{b}} \pm 11.29$ & $143.80^{b} \pm 16.14$ & $196.69^{b} \pm 13.94$ \\
\hline & Gr.3 & $201.89^{\mathrm{b}} \pm 14.00$ & $209.86^{\mathrm{bc}} \pm 11.06$ & $216.91^{\mathrm{bc}} \pm 9.13$ & $170.93^{\mathrm{c}} \pm 11.09$ & $200.25^{c} \pm 11.04$ & $208.44^{b} \pm 13.05$ \\
\hline & Gr.4 & $215.31^{\mathrm{b}} \pm 14.38$ & $228.27^{\mathrm{c}} \pm 13.92$ & $224.54^{\mathrm{c}} \pm 11.84$ & $194.53^{\mathrm{c}} \pm 16.54$ & $203.75^{c} \pm 14.80$ & $219.05^{\mathrm{b}} \pm 14.82$ \\
\hline \multirow{4}{*}{$\begin{array}{l}\text { LDH } \\
\text { (U/L) }\end{array}$} & Gr.1 & $185.09^{\mathrm{a}} \pm 10.54$ & $183.92^{\mathrm{a}} \pm 10.99$ & $182.51^{\mathrm{a}} \pm 7.75$ & $179.47^{\mathrm{a}} \pm 10.65$ & $178.82^{\mathrm{a}} \pm 12.62$ & $173.04^{\mathrm{a}} \pm 7.90$ \\
\hline & Gr.2 & $228.6^{\mathrm{b}} \pm 13.16$ & $234.16^{\mathrm{b}} \pm 13.97$ & $238.69^{\mathrm{b}} \pm 11.93$ & $218.74^{\mathrm{b}} \pm 13.24$ & $228.90^{\mathrm{b}} \pm 12.54$ & $231.94^{b} \pm 14.39$ \\
\hline & Gr.3 & $289.62^{b} \pm 11.13$ & $295.17^{\mathrm{c}} \pm 13.49$ & $327.42^{\mathrm{c}} \pm 11.42$ & $287.92^{b} \pm 12.38$ & $299.59^{c} \pm 14.42$ & $302.85^{c} \pm 13.98$ \\
\hline & Gr.4 & $388.65^{\mathrm{c}} \pm 15.04$ & $394.86^{\mathrm{d}} \pm 10.73$ & $419.22^{\mathrm{d}} \pm 14.43$ & $392.97^{\mathrm{c}} \pm 13.99$ & $396.15^{d} \pm 9.77$ & $409.97^{\mathrm{d}} \pm 11.81$ \\
\hline
\end{tabular}

Note: Bearing different superscripts in a column differ significantly $(\mathrm{P}<0.05)$. 
Table.4 Average enzymatic activities values in recovery groups at 104th day

\begin{tabular}{|c|c|c|c|}
\hline \multirow[t]{2}{*}{ Parameters Studied } & \multirow{2}{*}{$\begin{array}{c}\text { Groups } \\
\mathbf{N}=10\end{array}$} & Male & Female \\
\hline & & Mean \pm SE & Mean \pm SE \\
\hline \multirow{2}{*}{$\begin{array}{c}\text { AST } \\
\text { (U/L) }\end{array}$} & Gr.5 & $68.98^{\mathrm{a}} \pm 5.96$ & $77.01^{a} \pm 6.22$ \\
\hline & Gr.6 & $91.08^{\mathrm{a}} \pm 7.66$ & $87.25^{\mathrm{a}} \pm 5.84$ \\
\hline \multirow{2}{*}{$\begin{array}{c}\text { ALT } \\
(\mathbf{U} / \mathbf{L})\end{array}$} & Gr.5 & $29.21^{\mathrm{a}} \pm 3.04$ & $34.16^{\mathrm{a}} \pm 3.93$ \\
\hline & Gr.6 & $35.46^{\mathrm{a}} \pm 4.07$ & $38.65^{\mathrm{a}} \pm 4.90$ \\
\hline \multirow{2}{*}{$\begin{array}{c}\text { ALP } \\
\text { (U/L) }\end{array}$} & Gr.5 & $72.57^{\mathrm{a}} \pm 6.16$ & $77.02^{a} \pm 5.58$ \\
\hline & Gr.6 & $96.76^{\mathrm{a}} \pm 4.03$ & $104.70^{a} \pm 9.09$ \\
\hline \multirow{2}{*}{$\begin{array}{l}\text { LDH } \\
\text { (U/L) }\end{array}$} & Gr.5 & $188.83^{\mathrm{a}} \pm 12.58$ & $179.50^{\mathrm{a}} \pm 9.15$ \\
\hline & Gr.6 & $194.12^{\mathrm{a}} \pm 12.39$ & $191.69^{a} \pm 11.40$ \\
\hline
\end{tabular}

Note: Bearing different superscript in a column differ significantly $(\mathrm{P}<0.05)$.

Table.5 Liver / Kidney function parameters (Mean \pm SE) in different groups at different time intervals

\begin{tabular}{|c|c|c|c|c|c|c|c|}
\hline \multirow{2}{*}{$\begin{array}{l}\text { Parameters } \\
\text { Studied }\end{array}$} & \multirow{2}{*}{$\begin{array}{c}\text { Group } \\
\mathrm{N}=10\end{array}$} & \multicolumn{3}{|c|}{ Male } & \multicolumn{3}{|c|}{ Female } \\
\hline & & Day 28 & Day 56 & Day 90 & Day 28 & Day 56 & Day 90 \\
\hline \multirow{4}{*}{$\begin{array}{c}\text { Total } \\
\text { Protein } \\
\text { (gm/dl) }\end{array}$} & Gr.1 & $6.00^{\mathrm{a}} \pm 0.33$ & $6.25^{\mathrm{a}} \pm 0.33$ & $6.31^{\mathrm{a}} \pm 0.29$ & $6.19^{\mathrm{a}} \pm 0.19$ & $6.08^{\mathrm{a}} \pm 0.21$ & $6.20^{\mathrm{a}} \pm 0.16$ \\
\hline & Gr.2 & $7.81^{b} \pm 0.34$ & $7.94^{\mathrm{b}} \pm 0.30$ & $7.81^{b} \pm 0.28$ & $7.33^{b} \pm 0.36$ & $7.67^{b} \pm 0.30$ & $7.50^{b} \pm 0.36$ \\
\hline & Gr.3 & $8.46^{b} \pm 0.35$ & $8.63^{b c} \pm 0.28$ & $8.44^{b} \pm 0.36$ & $8.10 b^{c} \pm 0.38$ & $8.28 b^{c} \pm 0.40$ & $8.63^{c} \pm 0.41$ \\
\hline & Gr.4 & $8.21^{b} \pm 0.49$ & $9.27^{\mathrm{c}} \pm 0.32$ & $9.34^{\mathrm{c}} \pm 0.34$ & $8.72^{c} \pm 0.36$ & $9.10^{c} \pm 0.32$ & $9.15^{c} \pm 0.34$ \\
\hline \multirow{4}{*}{$\begin{array}{l}\text { Albumin } \\
\text { (gm/dl) }\end{array}$} & Gr.1 & $4.00^{\mathrm{a}} \pm 0.16$ & $3.99^{\mathrm{a}} \pm 0.21$ & $4.11^{\mathrm{a}} \pm 0.10$ & $4.11^{\mathrm{a}} \pm 0.17$ & $3.95^{\mathrm{a}} \pm 0.12$ & $4.00^{\mathrm{a}} \pm 0.14$ \\
\hline & Gr.2 & $3.58^{\mathrm{ab}} \pm 0.17$ & $3.56^{\mathrm{ab}} \pm 0.21$ & $3.54^{\mathrm{b}} \pm 0.17$ & $3.72^{\mathrm{a}} \pm 0.19$ & $3.42^{b} \pm 0.15$ & $3.35^{b} \pm 0.12$ \\
\hline & Gr.3 & $3.15^{\mathrm{bc}} \pm 0.20$ & $3.07^{b c} \pm 0.18$ & $2.96^{\mathrm{c}} \pm 0.18$ & $3.12^{b} \pm 0.15$ & $3.24^{b c} \pm 0.16$ & $3.10^{b} \pm 0.16$ \\
\hline & Gr. 4 & $2.93^{c} \pm 0.15$ & $2.89^{c} \pm 0.11$ & $2.81^{c} \pm 0.16$ & $3.17^{b} \pm 0.12$ & $2.96^{\mathrm{c}} \pm 0.13$ & $2.94^{b} \pm 0.17$ \\
\hline \multirow{4}{*}{$\begin{array}{l}\text { Globulin } \\
\text { (gm/dl) }\end{array}$} & Gr.1 & $2.00^{\mathrm{a}} \pm 0.21$ & $2.26^{\mathrm{a}} \pm 0.26$ & $2.20^{\mathrm{a}} \pm 0.27$ & $2.08^{\mathrm{a}} \pm 0.25$ & $2.13^{\mathrm{a}} \pm 0.23$ & $2.20^{\mathrm{a}} \pm 0.26$ \\
\hline & Gr.2 & $4.23^{b} \pm 0.48$ & $4.38^{b} \pm 0.42$ & $4.27^{b} \pm 0.37$ & $3.61^{b} \pm 0.49$ & $4.25^{\mathrm{b}} \pm 0.32$ & $3.85^{b} \pm 0.33$ \\
\hline & Gr.3 & $5.31^{b} \pm 0.31$ & $5.56^{\mathrm{c}} \pm 0.39$ & $5.48^{c} \pm 0.42$ & $4.98^{c} \pm 0.44$ & $5.04^{b} \pm 0.46$ & $5.53^{c} \pm 0.41$ \\
\hline & Gr.4 & $5.28^{b} \pm 0.46$ & $6.38^{\mathrm{c}} \pm 0.38$ & $6.53^{\mathrm{d}} \pm 0.46$ & $5.55^{\mathrm{c}} \pm 0.36$ & $6.14^{\mathrm{c}} \pm 0.33$ & $6.21^{c} \pm 0.44$ \\
\hline \multirow[t]{4}{*}{ A:G Ratio } & Gr.1 & $2.17^{\mathrm{a}} \pm 0.66$ & $2.02^{\mathrm{a}} \pm 0.26$ & $2.13^{\mathrm{a}} \pm 0.27$ & $2.26^{\mathrm{a}} \pm 0.29$ & $2.09^{\mathrm{a}} \pm 0.23$ & $2.14^{\mathrm{a}} \pm 0.31$ \\
\hline & Gr.2 & $1.03^{b} \pm 0.65$ & $0.93^{b} \pm 0.15$ & $0.94^{\mathrm{b}} \pm 0.15$ & $1.36^{\mathrm{b}} \pm 0.29$ & $0.87^{b} \pm 0.09$ & $1.02^{b} \pm 0.10$ \\
\hline & Gr.3 & $0.62^{b} \pm 0.19$ & $0.60^{b} \pm 0.09$ & $0.61^{b} \pm 0.12$ & $0.69^{c} \pm 0.08$ & $0.72^{b} \pm 0.10$ & $0.60^{b} \pm 0.05$ \\
\hline & Gr.4 & $0.58^{b} \pm 0.18$ & $0.47^{b} \pm 0.05$ & $0.47^{b} \pm 0.07$ & $0.60^{c} \pm 0.06$ & $0.49^{b} \pm 0.04$ & $0.51^{b} \pm 0.07$ \\
\hline \multirow{4}{*}{$\begin{array}{c}\text { Total } \\
\text { Bilirubin } \\
(\mathbf{m g} / \mathbf{d L})\end{array}$} & Gr.1 & $0.05^{\mathrm{a}} \pm 0.01$ & $0.05^{\mathrm{a}} \pm 0.01$ & $0.05^{\mathrm{a}} \pm 0.01$ & $0.04^{\mathrm{a}} \pm 0.00$ & $0.04^{\mathrm{a}} \pm 0.00$ & $0.05^{\mathrm{a}} \pm 0.00$ \\
\hline & Gr.2 & $0.07^{b} \pm 0.01$ & $0.09^{b} \pm 0.00$ & $0.09^{b} \pm 0.01$ & $0.07^{\mathrm{b}} \pm 0.00$ & $0.08^{b} \pm 0.00$ & $0.08^{b} \pm 0.01$ \\
\hline & Gr.3 & $0.08^{\mathrm{b}} \pm 0.01$ & $0.10^{\mathrm{b}} \pm 0.00$ & $0.09^{b} \pm 0.01$ & $0.07^{b} \pm 0.00$ & $0.08^{\mathrm{b}} \pm 0.00$ & $0.09^{b} \pm 0.00$ \\
\hline & Gr.4 & $0.09^{\mathrm{b}} \pm 0.00$ & $0.10^{\mathrm{b}} \pm 0.01$ & $0.10^{b} \pm 0.01$ & $0.08^{\mathrm{b}} \pm 0.00$ & $0.08^{\mathrm{b}} \pm 0.00$ & $0.09^{b} \pm 0.01$ \\
\hline \multirow{4}{*}{$\begin{array}{c}\text { Creatinine } \\
(\mathrm{mg} / \mathrm{dL})\end{array}$} & Gr.1 & $0.26^{a} \pm 0.03$ & $0.27^{\mathrm{a}} \pm 0.03$ & $0.25^{\mathrm{a}} \pm 0.02$ & $0.25^{\mathrm{a}} \pm 0.03$ & $0.20^{\mathrm{a}} \pm 0.01$ & $0.26^{\mathrm{a}} \pm 0.03$ \\
\hline & Gr.2 & $0.33^{\mathrm{a}} \pm 0.03$ & $0.36^{\mathrm{b}} \pm 0.05$ & $0.35^{\mathrm{ab}} \pm 0.04$ & $0.33^{\mathrm{a}} \pm 0.04$ & $0.34^{\mathrm{b}} \pm 0.04$ & $0.39^{b} \pm 0.04$ \\
\hline & Gr.3 & $0.42^{\mathrm{bc}} \pm 0.05$ & $0.48^{\mathrm{b}} \pm 0.05$ & $0.43^{\mathrm{b}} \pm 0.05$ & $0.45^{\mathrm{b}} \pm 0.04$ & $0.45^{\mathrm{c}} \pm 0.04$ & $0.44^{b} \pm 0.05$ \\
\hline & Gr.4 & $0.47^{\mathrm{c}} \pm 0.04$ & $0.54^{\mathrm{b}} \pm 0.04$ & $0.56^{\mathrm{c}} \pm 0.04$ & $0.49^{\mathrm{b}} \pm 0.04$ & $0.49^{c} \pm 0.03$ & $0.60^{c} \pm 0.03$ \\
\hline \multirow{4}{*}{$\begin{array}{c}\text { Blood } \\
\text { Urea } \\
(\mathbf{m g} / \mathbf{d L})\end{array}$} & Gr.1 & $28.05^{\mathrm{a}} \pm 1.72$ & $27.38^{\mathrm{a}} \pm 1.42$ & $25.18^{\mathrm{a}} \pm 1.69$ & $27.04^{\mathrm{a}} \pm 2.03$ & $26.94^{\mathrm{a}} \pm 1.48$ & $25.69^{a} \pm 129$ \\
\hline & Gr.2 & $37.38^{\mathrm{b}} \pm 1.98$ & $39.42^{\mathrm{b}} \pm 2.85$ & $36.30^{\mathrm{b}} \pm 1.50$ & $37.15^{\mathrm{b}} \pm 1.39$ & $40.83^{\mathrm{b}} \pm 3.34$ & $36.86^{b} \pm 1.64$ \\
\hline & Gr.3 & $41.88^{\mathrm{bc}} \pm 2.67$ & $47.99^{b c} \pm 3.97$ & $51.38^{\mathrm{c}} \pm 4.90$ & $42.53^{\mathrm{b}} \pm 2.39$ & $45.37^{\mathrm{bc}} \pm 3.44$ & $50.87^{c} \pm 3.34$ \\
\hline & Gr.4 & $47.48^{\mathrm{c}} \pm 2.74$ & $53.10^{c} \pm 4.00$ & $53.97^{\mathrm{c}} \pm 4.03$ & $49.32^{\mathrm{b}} \pm 3.60$ & $53.10^{c} \pm 3.61$ & $61.28^{d} \pm 2.84$ \\
\hline \multirow{4}{*}{$\begin{array}{l}\text { Glucose } \\
(\mathrm{mg} / \mathrm{dL})\end{array}$} & Gr.1 & $76.23^{\mathrm{a}} \pm 4.99$ & $77.54^{\mathrm{a}} \pm 5.64$ & $72.67^{\mathrm{a}} \pm 5.46$ & $73.36^{a} \pm 6.16$ & $72.12^{\mathrm{a}} \pm 5.83$ & $75.12^{a} \pm 6.26$ \\
\hline & Gr.2 & $92.27^{\mathrm{b}} \pm 5.29$ & $95.49^{\mathrm{b}} \pm 4.21$ & $94.20^{\mathrm{b}} \pm 6.21$ & $93.93^{\mathrm{b}} \pm 6.75$ & $92.94^{\mathrm{b}} \pm 7.48$ & $100.01^{b} \pm 4.66$ \\
\hline & Gr.3 & $94.72^{\mathrm{b}} \pm 4.10$ & $101.09^{b c} \pm 5.56$ & $100.38^{\mathrm{b}} \pm 5.21$ & $95.50^{\mathrm{b}} \pm 5.89$ & $97.13^{\mathrm{b}} \pm 6.43$ & $105.61^{b} \pm 4.88$ \\
\hline & Gr.4 & $99.80^{b} \pm 5.51$ & $112.52^{c} \pm 5.72$ & $108.42^{c} \pm 5.74$ & $98.28^{b} \pm 6.62$ & $106.51^{b} \pm 5.56$ & $109.86^{b} \pm 4.74$ \\
\hline
\end{tabular}

Note: Bearing different superscripts in a column differ significantly $(\mathrm{P}<0.05)$. 
Table.6 Liver / Kidney function parameters (Mean \pm SE) in recovery groups at 104th day

\begin{tabular}{|c|c|c|c|}
\hline \multirow[t]{2}{*}{ Parameters Studied } & \multirow{2}{*}{$\begin{array}{c}\text { Groups } \\
\mathbf{N}=10\end{array}$} & Male & Female \\
\hline & & Mean \pm SE & $\operatorname{Mean} \pm$ SE \\
\hline \multirow{2}{*}{$\begin{array}{l}\text { Total Protein } \\
\text { (gm/dl) }\end{array}$} & Gr.5 & $6.56^{\mathrm{a}} \pm 0.20$ & $6.30^{a} \pm 0.21$ \\
\hline & Gr.6 & $6.63^{\mathrm{a}} \pm 0.21$ & $6.34^{a} \pm 0.21$ \\
\hline \multirow{2}{*}{$\begin{array}{l}\text { Albumine } \\
\text { (gm/dl) }\end{array}$} & Gr.5 & $4.30^{\mathrm{a}} \pm 0.28$ & $4.03^{a} \pm 0.11$ \\
\hline & Gr.6 & $4.10^{\mathrm{a}} \pm 0.22$ & $3.99^{a} \pm 0.12$ \\
\hline \multirow{2}{*}{$\begin{array}{l}\text { Globulin } \\
\text { (gm/dl) }\end{array}$} & Gr.5 & $2.27^{\mathrm{a}} \pm 0.33$ & $2.27^{\mathrm{a}} \pm 0.24$ \\
\hline & Gr.6 & $2.53^{\mathrm{a}} \pm 0.21$ & $2.35^{\mathrm{a}} \pm 0.19$ \\
\hline \multirow[t]{2}{*}{ A/G Ratio } & Gr.5 & $2.45^{\mathrm{a}} \pm 0.47$ & $1.99^{a} \pm 0.22$ \\
\hline & Gr.6 & $1.76^{\mathrm{a}} \pm 0.23$ & $1.82^{a} \pm 0.17$ \\
\hline \multirow{2}{*}{$\begin{array}{l}\text { Total Bilirubin } \\
\quad(\mathrm{mg} / \mathrm{dL})\end{array}$} & Gr.5 & $0.05^{\mathrm{a}} \pm 0.01$ & $0.05^{\mathrm{a}} \pm 0.01$ \\
\hline & Gr.6 & $0.05^{\mathrm{a}} \pm 0.01$ & $0.05^{\mathrm{a}} \pm 0.01$ \\
\hline \multirow{2}{*}{$\begin{array}{c}\text { Criatinine } \\
(\mathbf{m g} / \mathbf{d L})\end{array}$} & Gr.5 & $0.28^{\mathrm{a}} \pm 0.02$ & $0.24^{\mathrm{a}} \pm 0.02$ \\
\hline & Gr.6 & $0.30^{\mathrm{a}} \pm 0.03$ & $0.29^{\mathrm{a}} \pm 0.02$ \\
\hline \multirow{2}{*}{$\begin{array}{l}\text { Blood Urea } \\
\text { (mg/dL) }\end{array}$} & Gr.5 & $27.50^{\mathrm{a}} \pm 1.69$ & $27.57^{a} \pm 1.59$ \\
\hline & Gr.6 & $31.59^{\mathrm{a}} \pm 2.19$ & $29.98^{a} \pm 2.57$ \\
\hline \multirow{2}{*}{$\begin{array}{l}\text { Glucose } \\
\text { (mg/dL) }\end{array}$} & Gr.5 & $75.28^{\mathrm{a}} \pm 4.96$ & $77.19^{\mathrm{a}} \pm 5.49$ \\
\hline & Gr.6 & $77.49^{\mathrm{a}} \pm 4.47$ & $78.38^{\mathrm{a}} \pm 4.74$ \\
\hline
\end{tabular}

Note: Bearing different superscripts in a column differ significantly $(\mathrm{P}<0.05)$.

Table.7 Mean $( \pm$ SE) lipid profile values in different groups at different time intervals

\begin{tabular}{|c|c|c|c|c|c|c|c|}
\hline \multirow{2}{*}{$\begin{array}{l}\text { Parameters } \\
\text { Studied }\end{array}$} & \multirow{2}{*}{$\begin{array}{l}\text { Groups } \\
\mathrm{N}=10\end{array}$} & \multicolumn{3}{|c|}{ Male } & \multicolumn{3}{|c|}{ Female } \\
\hline & & Day 28 & Day 56 & Day 90 & Day 28 & Day 56 & Day 90 \\
\hline \multirow{4}{*}{$\begin{array}{c}\text { Cholesterol } \\
(\mathrm{mg} / \mathrm{dl})\end{array}$} & Gr.1 & $31.55^{\mathrm{a}} \pm 1.16$ & $29.98^{\mathrm{a}} \pm 1.55$ & $31.87^{\mathrm{a}} \pm 1.27$ & $29.88^{\mathrm{a}} \pm 1.48$ & $29.12^{\mathrm{a}} \pm 1.30$ & $31.60^{\mathrm{a}} \pm 1.33$ \\
\hline & Gr.2 & $42.16^{\mathrm{b}} \pm 2.95$ & $39.36^{\mathrm{b}} \pm 2.58$ & $45.78^{\mathrm{b}} \pm 2.89$ & $40.25^{\mathrm{b}} \pm 3.30$ & $46.06^{\mathrm{b}} \pm 3.00$ & $47.75^{b} \pm 2.18$ \\
\hline & Gr.3 & $47.39^{\mathrm{bc}} \pm 2.80$ & $48.86^{\mathrm{c}} \pm 2.88$ & $51.90^{\mathrm{bc}} \pm 2.98$ & $45.47^{\mathrm{bc}} \pm 2.76$ & $48.99^{\mathrm{bc}} \pm 2.87$ & $50.80^{b} \pm 2.94$ \\
\hline & Gr.4 & $53.65^{\mathrm{c}} \pm 2.08$ & $54.69^{c} \pm 2.29$ & $55.93^{\mathrm{c}} \pm 3.08$ & $52.61^{\mathrm{c}} \pm 2.24$ & $53.40^{c} \pm 1.94$ & $59.23^{c} \pm 2.43$ \\
\hline \multirow{4}{*}{$\begin{array}{l}\text { Triglyceri } \\
\text { de (mg/dl) }\end{array}$} & Gr.1 & $73.27^{\mathrm{a}} \pm 5.99$ & $75.01^{\mathrm{a}} \pm 4.84$ & $79.14^{\mathrm{a}} \pm 6.74$ & $79.54^{\mathrm{a}} \pm 5.88$ & $81.58^{\mathrm{a}} \pm 5.35$ & $78.39^{\mathrm{a}} \pm 5.34$ \\
\hline & Gr.2 & $108.05^{\mathrm{b}} \pm 6.83$ & $121.87^{b} \pm 7.60$ & $120.13^{b} \pm 6.17$ & $116.26^{\mathrm{b}} \pm 7.18$ & $114.33^{b} \pm 7.31$ & $119.58^{b} \pm 8.47$ \\
\hline & Gr.3 & $122.85^{\mathrm{b}} \pm 7.81$ & $137.53^{\mathrm{b}} \pm 8.44$ & $148.23^{\mathrm{b}} \pm 5.62$ & $120.61^{b} \pm 6.35$ & $131.37^{\mathrm{bc}} \pm 7.27$ & $136.61^{b c} \pm 8.69$ \\
\hline & Gr.4 & $126.96^{\mathrm{b}} \pm 7.58$ & $142.96^{\mathrm{b}} \pm 8.02$ & $153.79^{b} \pm 6.67$ & $128.84^{\mathrm{b}} \pm 7.47$ & $143.16^{\mathrm{c}} \pm 8.29$ & $152.40^{c} \pm 9.02$ \\
\hline \multirow{4}{*}{$\begin{array}{c}\text { Total } \\
\text { Lipid } \\
\text { (mg/dl) }\end{array}$} & Gr.1 & $709.64^{\mathrm{a}} \pm 33.24$ & $700.78^{\mathrm{a}} \pm 18.20$ & $707.29^{\mathrm{a}} \pm 28.33$ & $638.30^{\mathrm{a}} \pm 31.54$ & $658.81^{\mathrm{a}} \pm 26.30$ & $\begin{array}{c}647.15^{\mathrm{a}} \pm 49.1 \\
0\end{array}$ \\
\hline & Gr.2 & $744.37^{\mathrm{ab}} \pm 34.51$ & $784.47^{b} \pm 42.62$ & $795.05^{b} \pm 25.78$ & $790.70^{b} \pm 34.47$ & $799.98^{\mathrm{b}} \pm 34.39$ & $855.52^{\mathrm{b}} \pm 29.94$ \\
\hline & Gr.3 & $810.23^{b c} \pm 34.82$ & $827.40^{\mathrm{bc}} \pm 27.89$ & $879.01^{c} \pm 33.89$ & $820.63^{b} \pm 48.08$ & $873.28^{\mathrm{bc}} \pm 23.32$ & $911.15^{b} \pm 24.93$ \\
\hline & Gr.4 & $863.24^{c} \pm 26.12$ & $887.05^{c} \pm 14.51$ & $926.23^{c} \pm 15.30$ & $870.96^{b} \pm 21.45$ & $949.27^{c} \pm 33.19$ & $937.24^{b} \pm 21.54$ \\
\hline
\end{tabular}

Note: Bearing different superscripts in a column differ significantly $(\mathrm{P}<0.05)$. 
Table.8 Mean $( \pm$ SE) lipid profile values in recovery groups at 104th day

\begin{tabular}{|c|c|c|c|}
\hline Parameters Studied & Groups & Male & Female \\
\cline { 3 - 4 } & N=10 & Mean \pm SE & Mean \pm SE \\
\hline Total Cholesterol & Gr.5 & $33.53^{\mathrm{a}} \pm 1.70$ & $\mathbf{3 2 . 7 6}^{\mathrm{a}} \pm \mathbf{2 . 0 3}$ \\
\cline { 3 - 4 }$(\mathbf{m g} / \mathbf{d l})$ & Gr.6 & $49.12^{\mathrm{b}} \pm 2.47$ & $\mathbf{4 5 . 2 4}^{\mathrm{b}} \pm \mathbf{2 . 0 3}$ \\
\hline Triglyceride & Gr.5 & $87.28^{\mathrm{a}} \pm 4.82$ & $\mathbf{8 7 . 9 6}^{\mathrm{a}} \pm \mathbf{4 . 9 7}$ \\
\hline (mg/dl) & Gr.6 & $125.20^{\mathrm{b}} \pm 4.63$ & $\mathbf{1 3 3 . 7 8}^{\mathrm{b}} \pm \mathbf{5 . 2 4}$ \\
\hline Total Lipid & Gr.5 & $703.15^{\mathrm{a}} \pm 26.73$ & $\mathbf{7 0 9 . 2}^{\mathrm{a}} \pm \mathbf{2 1 . 6 6}$ \\
\hline (mg/dl) & Gr.6 & $\mathbf{8 4 2 . 8 6}^{\mathrm{b}} \pm \mathbf{2 0 . 9 5}$ & $\mathbf{8 7 4 . 8 2}^{\mathbf{b}} \pm \mathbf{1 7 . 5 5}$ \\
\hline
\end{tabular}

Note: Bearing different superscripts in a column differ significantly $(\mathrm{P}<0.05)$.

Table.9 Mean $( \pm$ SE) serum electrolytes values in different groups at different time intervals

\begin{tabular}{|c|c|c|c|c|c|c|c|}
\hline \multirow{2}{*}{$\begin{array}{l}\text { Parameters } \\
\text { Studied }\end{array}$} & \multirow{2}{*}{\begin{tabular}{c|} 
Groups \\
$\mathbf{N}=10$
\end{tabular}} & \multicolumn{3}{|c|}{ Male } & \multicolumn{3}{|c|}{ Female } \\
\hline & & Day 28 & Day 56 & Day 90 & Day 28 & Day 56 & Day 90 \\
\hline \multirow{4}{*}{$\begin{array}{l}\text { Sodium } \\
(\mathrm{mmol} / \mathrm{L})\end{array}$} & Gr.1 & $142.86^{\mathrm{a}} \pm 1.77$ & $144.88^{\mathrm{a}} \pm 3.00$ & $149.11^{\mathrm{a}} \pm 2.21$ & $143.89^{\mathrm{a}} \pm 2.03$ & $147.16^{\mathrm{a}} \pm 2.41$ & $148.54^{\mathrm{a}} \pm 2.21$ \\
\hline & Gr.2 & $140.70^{\mathrm{a}} \pm 1.78$ & $128.47^{\mathrm{b}} \pm 2.32$ & $126.58^{b} \pm 2.08$ & $138.00^{\mathrm{ab}} \pm 2.84$ & $138.72^{\mathrm{ab}} \pm 3.70$ & $127.99^{b} \pm 2.45$ \\
\hline & Gr.3 & $139.93^{\mathrm{a}} \pm 1.96$ & $117.23^{\mathrm{c}} \pm 2.30$ & $114.64^{c} \pm 2.81$ & $136.62^{\mathrm{ab}} \pm 3.30$ & $132.52^{\mathrm{b}} \pm 2.51$ & $120.06^{b c} \pm 3.19$ \\
\hline & Gr. 4 & $137.67^{\mathrm{a}} \pm 1.97$ & $112.23^{\mathrm{c}} \pm 2.01$ & $108.30^{c} \pm 1.94$ & $130.57^{\mathrm{c}} \pm 1.86$ & $118.62^{\mathrm{c}} \pm 4.36$ & $112.06^{c} \pm 3.24$ \\
\hline \multirow{4}{*}{$\begin{array}{c}\text { Potassium } \\
(\mathrm{mmol} / \mathrm{L})\end{array}$} & Gr.1 & $4.91^{\mathrm{a}} \pm 0.24$ & $4.58^{\mathrm{a}} \pm 0.22$ & $4.78^{\mathrm{a}} \pm 0.21$ & $4.79^{\mathrm{a}} \pm 0.15$ & $4.77^{\mathrm{a}} \pm 0.18$ & $4.65^{\mathrm{a}} \pm 0.22$ \\
\hline & Gr.2 & $4.56^{\mathrm{a}} \pm 0.23$ & $4.34^{\mathrm{a}} \pm 0.24$ & $4.49^{\mathrm{a}} \pm 0.14$ & $4.72^{\mathrm{a}} \pm 0.11$ & $4.54^{\mathrm{a}} \pm 0.12$ & $4.34^{\mathrm{a}} \pm 0.17$ \\
\hline & Gr.3 & $4.64^{\mathrm{a}} \pm 0.26$ & $4.31^{\mathrm{a}} \pm 0.27$ & $4.34^{\mathrm{a}} \pm 0.18$ & $4.66^{\mathrm{a}} \pm 0.17$ & $4.48^{\mathrm{a}} \pm 0.13$ & $4.22^{\mathrm{a}} \pm 0.06$ \\
\hline & Gr. 4 & $4.55^{\mathrm{a}} \pm 0.17$ & $3.95^{\mathrm{a}} \pm 0.18$ & $4.23^{\mathrm{a}} \pm 0.15$ & $4.58^{\mathrm{a}} \pm 0.11$ & $4.37^{\mathrm{a}} \pm 0.15$ & $4.09^{\mathrm{a}} \pm 0.18$ \\
\hline \multirow{4}{*}{$\begin{array}{l}\text { Chloride } \\
\text { (mEq/L) }\end{array}$} & Gr.1 & $105.46^{\mathrm{a}} \pm 2.84$ & $103.07^{\mathrm{a}} \pm 3.17$ & $104.06^{\mathrm{a}} \pm 2.53$ & $104.16^{\mathrm{a}} \pm 1.20$ & $103.31^{\mathrm{a}} \pm 1.16$ & $104.42^{\mathrm{a}} \pm 1.59$ \\
\hline & Gr.2 & $102.61^{\mathrm{ab}} \pm 1.82$ & $98.08^{\mathrm{ab}} \pm 2.47$ & $97.32^{\mathrm{ab}} \pm 1.62$ & $101.03^{\mathrm{ab}} \pm 1.97$ & $98.21^{\mathrm{b}} \pm 1.66$ & $\begin{array}{c}97.71^{b} \pm 1.1 \\
4\end{array}$ \\
\hline & Gr.3 & $100.44^{\mathrm{ab}} \pm 2.92$ & $98.67^{\mathrm{ab}} \pm 2.33$ & $94.87^{b} \pm 2.43$ & $99.06^{\mathrm{b}} \pm 1.14$ & $97.34^{\mathrm{b}} \pm 1.28$ & $\begin{array}{c}96.10^{b} \pm 1.1 \\
6\end{array}$ \\
\hline & Gr.4 & $96.48^{b} \pm 3.07$ & $93.21^{b} \pm 1.65$ & $91.71^{b} \pm 1.75$ & $\begin{array}{c}97.10^{b} \pm 1.1 \\
4\end{array}$ & $\begin{array}{c}96.25^{b} \pm 1.2 \\
4\end{array}$ & $\begin{array}{c}94.03^{b} \pm 0.9 \\
9\end{array}$ \\
\hline
\end{tabular}

Note: Bearing different superscripts in a column differ significantly $(\mathrm{P}<0.05)$. Mean expressed as Mean $\pm \mathrm{SE}$

Table.10 Mean $( \pm$ SE) serum electrolytes values in recovery groups at 104 th day

\begin{tabular}{|c|c|c|c|}
\hline \multirow[t]{2}{*}{ Parameters Studied } & \multirow{2}{*}{$\begin{array}{c}\text { Groups } \\
\mathrm{N}=10\end{array}$} & Male & Female \\
\hline & & Mean \pm SE & Mean \pm SE \\
\hline \multirow{2}{*}{$\begin{array}{l}\text { Sodium } \\
(\mathrm{mmol} / \mathrm{L})\end{array}$} & Gr.5 & $145.59^{\mathrm{a}} \pm 2.19$ & $145.64^{\mathrm{a}} \pm 2.15$ \\
\hline & Gr.6 & $142.41^{\mathrm{a}} \pm 2.10$ & $142.33^{\mathrm{a}} \pm 3.08$ \\
\hline \multirow{2}{*}{$\begin{array}{c}\text { Potassium } \\
(\mathrm{mmol} / \mathrm{L})\end{array}$} & Gr.5 & $4.77^{\mathrm{a}} \pm 0.14$ & $4.72^{\mathrm{a}} \pm 0.18$ \\
\hline & Gr.6 & $4.73^{\mathrm{a}} \pm 0.15$ & $4.72^{\mathrm{a}} \pm 0.17$ \\
\hline \multirow{2}{*}{$\begin{array}{l}\text { Chloride } \\
(\mathrm{mEq} / \mathrm{L})\end{array}$} & Gr.5 & $103.89^{\mathrm{a}} \pm 2.94$ & $105.79^{\mathrm{a}} \pm 1.55$ \\
\hline & Gr.6 & $102.25^{\mathrm{a}} \pm 1.64$ & $103.49^{\mathrm{a}} \pm 1.88$ \\
\hline
\end{tabular}

Note: Bearing different superscripts in a column differ significantly $(\mathrm{P}<0.05)$. 
In such conditions carbohydrates are not available to body tissues due to insulin deficiency resulting energy crisis. As such most of the energy is derived from fats. The fat stored in adipose tissue is then hydrolysed and the amount of free fatty acids in blood is increased producing a surge in serum total lipid concentration (Bushan et al., 2013b). These results are in agreement with those reported by Shalaby and Abdel-Latif (2016). Increased level of various total lipids could not become normal even after withdrawal of treatment for two weeks and this supported the findings of Shalaby and Abdel-Latif (2016). A significant $(\mathrm{P}<0.05)$ decrease level in sodium and chlorides in sera was seen in rats of treated Gr.2, 3 and 4 at interval period $\left(28^{\text {th }}, 56^{\text {th }}\right.$ and $\left.90^{\text {th }}\right)$ in either sex of rats but the sodium level did not affects in male at $28^{\text {th }}$ day in all the groups (Table 9). The serum electrolyte value in high dose recovery group (Gr.6) represented that the value became normal in two weeks withdrawal of treatment (Table 10). The beta cyfluthrin causing hyponatremia and hypochloremia might be attributed to the plugging of sodium and chloride channels at their gate in the brain (Narahashi, 2000). The present investigation is also affirmated by the past findings of Soderlund, 2012; Lian et al., (1991) and Rao and Rao (1997) after intoxication of different pyrethroids.

In conclusion, beta cyfluthrin oral treatment for ninety days with fourteen days recovery in wistar rats has decrease in $\mathrm{Hb}$ concentration, $\mathrm{RBCs}$ count, haematocrit, $\mathrm{MCH}$, platelets, lymphocytes occurred whereas an increase was seen in TLC and neutrophil count. Also significantly changes in the serum AST, ALT, ALP, LDH, creatinine, blood urea nitrogen, glucose and total bilirubin, total cholesterol, triglyceride and total lipids, sodium and chlorides levels in both males and females. Changes in clinical pathological parameters are indicative of adverse effects of beta cyfluthrin on haematolo-biliary system, liver and kidney like vital organs in wistar rats at dose level tested.

\section{References}

Abbassy, M. A. and Mossa, A. T. H. 2012. Haemato-biochemical effects of formulated and technical cypermethrin and deltamethrin insecticides in male rats. J. Pharmacol. Toxicol. 7: 1-10.

Ahmad, M., Hussain, I., Khan, A. and Najibur-Rehman, M. 2009. Deleterious effects of cypermethrin on semen characteristics and testes of dwarf goats (Capra hircus). Exp. Toxicol. Pathol. 61: 339-346.

Bhushan, B., Pande, S., Saxena N. and Saxena P. N. 2013a Serum biochemical responses under stress of cypermethrin in albino rat. Environmental and Experimental Biology 11:81-89.

Bhushan, B., Saxena, P. N. and Saxena, N. 2013b. Bichemical and histological changes in rat liver caused by cypermethrin and beta cyfluthrin. Arh. Hig. Rada Toksikol. 64:57-67.

Fetoui, H., Garoui, E. M. and Zeghal, N. 2009. Lambda-cyhalothrin induced biochemical and histopathological changes in the liver of rats: Ameliorative effect of ascorbic acid. Exp. Toxicol. Pathol. 61:189-196.

Gupta, P. K. and Kumar, S. 1991. Cumulative toxicity of deltamethrin in mice. $J$. Environ. Biol. 12(1): 45-50.

Guyton, A. C. and Hall, J. E. 2001. Textbook of Medical Physiology. 10th ed. Prism Books Limited, Bangalore, India. pp. 1148.

Hayes, W. and Laws, E. 1991. Handbook of Pesticide Toxicology. Vol.3, Academic Press Inc., New York, San Diego, pp. 1190. 
Hussain, S., Khan, M. Z., Khan, A., Javed, I. and Asi, M. R. 2009. Toxicopathological effects in rats induced by concurrent exposure to aflatoxin and cypermethrin. Toxicology. 53: 33-41.

Jain, N., Sharma, P., Sharma, N. and Joshi, S. C. 2009. Haemato-biochemical profile following sub acute toxicity of malathion in male albino rats. Pharmacology online 2: 500-506.

Lian, Y., Shapiro, J. I. and Chan, L. 1991. Study of brain electrolytes and organic osmolytes during correction of chronic hyponatremia. Journal of Clinical Investigation 88: 303-309.

Mani, U., Prasad, A. K., Kumar, S. V., Kumar, P., Kumar, K., Lal, K., Maji, B. K. and Dutta, K. K. 2004. Hepatotoxic alterations induced by sub chronic exposure of rats to formulated fenevalerate (20\% EC) by nose only inhalation. Biomed. Environ Sci. 17: 309-314.

Narahashi, T. 2000. Neuroreceptors and ion channels as the basis for drug action: Past, present, and future. J. Pharmacol. Exp. Ther. 294: 1-26.

Okuno, Y., Ito, S., Seki, T., Hiromori, T., Murakami, A. L., Kadota, T. and Miyamoto, I. 1986. Fenvalerate induced granulomatous changes in rats and mice. J. Toxicol. Sci. 11: 53-66.

Pande, S. 2001. Effect of synthetic pyrethroids on certain Haematobiochemical parameters of Rattus norvegicus. Ph.D. Thesis, Dr. B.R. Ambedkar University, Agra.

Rao, G. V. and Rao, K. S. 1997. Modulation of potassium across synaptosomes of rat brain by synthetic pyrethroids. Journal of Neurological Science 147(2): 127-33.

Rifat, F., Sharma, M., Srivastava, P. and Sisodia, R. 2012. Effects of Cyfluthrin on Biochemical and Histopathological Alterations in Liver of Swiss Albino
Mice. Int. J. Scient. Res. Rev. 1(2): 112.

Sakr, S. A. 1999. Pyrethroid inhalation induced hepatotoxicity in albino rats. Oxford Res. Forum J. 1: 27-31.

Samia, M. M., Hala, F. A. and Mossa, A. H. 2017. Adverse effects of sixty days subchronic exposure to beta cyfluthrin on male rats. J. Envorn. Sci. Technol. 10:112.

Sayim, F., Yavasolglu, N. U. K., Uyanikgil, Y., Aktug, H., Yavasolglu, A. and Turgut, M. 2005. Neurotoxic effects of cypermethrin in Wistar rats: a hematological, biochemical and histopathological study. J. Health Sci. 51: 300-307.

Shakoori, A. R., Ali, S. S. and Saleem, M. A. 1988. Effects of six months feeding of cypermethrin on blood and liver of Albino rats. J.Biochem. Mol. Toxicol. 3: 59-71.

Shakoori, A. R., Aziz, F., Alam, J. and Ali, S. S. 1990.Toxic effects of talastar, a new synthetic pyrethroid, on blood and liver of rabbit. Pakistan J. Zool. 23: 289-300.

Shalaby, S. E. M. and Abdel-Latif, A. M. 2016. Preventive Action of Ascorbic Acid and $\beta$-Carotene from BetaCyfluthrin Insecticide Toxicity on Rats. Int. J. of Pharm Tech Res. 9(12): 243250.

Snedecor, G.W. and Cochran, W.G. (1980) Statistical Methods. 7th Edition, Iowa State University Press, Ames.

Soderlund, D. M. 2012. Molecular mechanisms of pyrethroids insecticide neurotoxicity: Recent advances. Arch. Toxicol. 86(2): 165-181.

Tuzmen, N., Candan, N., Kaya, E. and Demiryas, N. 2008. Biochemical effects of chlorpyrifos and deltamethrin on altered antioxidative defense mechanisms and lipid peroxidation in rat liver. Cell Biochem. Funct. 26(1): $119-124$. 
Verma, R., Awasthi, K. K., Soni, I. and John, P. J. 2013. Evaluation of cytogenetic effect of beta cyfluthrin in Swiss albino mice. Int. J. Curr. Microbiol. App. Sci. 2(6): 30-40.

Waggas, A. M. 2013. Biochemical and histological effects of cyfluthrin on liver and kidney of quail (Coturnix couternix): potentiating role of peg. Global Veterinaria. 10(5): 524-533.

Wang, X. Z., Liu, S. S., Sun, Y., Wu, J. Y., Zhou, Y. L. and Zhang, J. H. 2009. Beta-cypermethrin impairs reproductive function in male mice by inducing oxidative stress. Theriogenology. 72:
599-611.

Wolansky, M. J. and Crofton, K. M. 2006. Relative Potencies for Acute Effects of Pyrethroids on Motor Function in Rats. Toxicological Science 89(1): 271-277.

Yadav, E. and Saxena, P. N. (2014). Toxicological effects of some type II pyrethroids on serum aminotransferase enzymes in albino rats. J. Exp. Zool. India 17(1): 231-234.

Yousef, M. I., Awad, T. I. and Mohamed, E. H. 2006. Deltamethrin-induced oxidative damage and biochemical alterations in rat and its attenuation by Vitamin E. Toxicology 227: 240-247.

\section{How to cite this article:}

Parmar, H.C., J.K. Raval, J.M. Patel, P.D. Vihol, I.H. Kalyani and Prasad, M.C. 2019. Haemato-biochemical Study: Induced Beta Cyfluthrin Repeated Toxicity with Reversal on Wistar Rats. Int.J.Curr.Microbiol.App.Sci. 8(03): 100-111.

doi: https://doi.org/10.20546/ijcmas.2019.803.015 